\title{
LOS MODELOS EN LAS JUSTAS POÉTICAS ARAGONESAS DEL SIGLO XVII
}

Hace ya años, Dámaso Alonso se refería, con acierto, a la necesidad de incorporar el análisis de las justas poéticas a los estudios literarios, aunque de la lectura de centones de forzados versos sólo se deduzca una cierta calidad en contadas ocasiones:

"Se canta allí con temas impuestos (y a veces muy extravagantes) [...] y a ellas concurren todas las medianías, todos los seguidores, los oscurecidos, los que no tienen nada que decir, ni auditorio para sus versos»'.

Cuanto sigue, refleja exclusivamente un aspecto parcial del amplio campo en el que crece esta poesía de certámenes: el de los modelos propuestos en Aragón a partir de $1599^{2}$. Pues, más allá de la imposible

' «Versos plurimembres y poemas correlativos», tirada aparte de la RABM, 49. Madrid, 1949, p. 89.

${ }^{2}$ Sobre ello traté ampliamente en la segunda parte de mi tesis ductoral, en curso de publicación, La poesía aragonesa del siglo XVII y el culteranismo (Universidad de Barcelona, 14 de abril de 1972. Vid. José María Castro y Calvo, Justas poéticas aragonesas del siglo XVII, Zaragoza, 1937. Ricardo del Arco, La Erudición Aragonesa en el siglo XVII en torno a Lastanosa, Madrid, 1934 y La Erudición Española en el sigho XVII y el cronista de Aragón Andrés de Uztarroz, Madrid, 1950. Di notica del culteranismo en Aragón en mi introducción a las Rimas de Juan de Moncayo, Madrid, Clásicos Castellanos, 1976 y en La poesía aragonesa del siglo XVII (Ráces culteranas), Zaragoza, 1979. Para la literatura de esta región, véase el reciente estudio de Manuel Alvar, Aragón, literatura y ser histórico, Zaragoza, 1977. 
justa quijotesca del arnés, Aragón es una de las regiones españolas que más contribuyeron a este tipo de festejos públicos a lo largo del Siglo de Oro ${ }^{3}$.

La influencia de Góngora, tan abundante en los versos de Juan de Moncayo, Andrés de Uztarroz, Felices de Cáceres, José Navarro, Juan Nadal, Miguel de Dicastillo y Diez y Foncalda, por citar a algunos de los que escribieron "en culto", llegó a evidenciarse en los mismos certámenes, como ocurrió en toda España ${ }^{4}$. Son prueba de ello los versos que encontramos a partir de 1617, con el Certamen al traslado de las reliquias de San Ramón Nonat, celebrado en Zaragoza, seguido por los que esa misma ciudad dedicó a fray Luis de Aliaga en una justa celebrada en 1619, junto con el de la Cofradía de la Sangre de Ciristo (1621) y el dedicado en 1628 a la Virgen del Pilar, que desató un "comento burlesco" anticulterano". La crítica apunta fundamentalmente contra el joven poeta Felices de Cáceres, al que van dedicados una canción y un romance en el Cancionero de 1628. Pero los tiros van dirigidos contra toda la maquinaria del poeta cordobés ("Para este goço elijo/no poemas de estilo culterano, /sino genio cathólico christiano"), proponiéndose a Lope como paradigma de la poesía ortodoxa. La Academia de los Anhelantes aportó en 1634 mayores testimonios en el Certamen a Santo Domingo de $\mathrm{Val}$, en donde se observa una profunda veta gongorina en la que ahondan posteriores justas zaragozanas: el Certamen poético de Nuestra Señora de Cogullada (1643) y el dedicado en 1646 a la muerte del príncipe Baltasar Carlos. A partir de esta fecha, es Huesca la que recoge esta tendencia en una de las justas más importantes de la región, la Palestra numerosa austriaca, celebrada en 1650 . No encuentro la

\footnotetext{
${ }^{3}$ Por razones de espacio, omito la enumeración de todas las justas. Las bases bibliográficas son, fundamentalmente: Alenda y Mira, Relaciones de las solemnidades y fiestas públicas de España, Madrid, 1903, J. Simón Díaz, Justas poéticas del Siglo de Oro, Madrid, 1962, y en particular, Latassa, Bibliotecas antigua y nueva de escritores aragoneses, aumentada y refundida por M. Gómez Uriel, Zaragoza, 1884-1886, J. M. Sánchez, Bibliografía aragonesa del siglo xv, Madrid, 1914 y Jiménez Catalán, Ensayo de una tipografia zaragozana del siglo XVII, Zaragoza, 1925.

- Millé, J.: «El papel de la nueva poesía (Lope, Góngora y los orígenes del culteranismo)», Estudios de Literatura española, La Plata, 1928, pp. 193-206). Joaquín de Entrambasguas, Estudios sobre Lope, Madrid, 1967, II, pp. 527-605. En Aragón decrece considerablemente la celebración de justas a partir de 1661 . El culteranismo afecta a la primera mitad del siglo, sobre todo. Una muestra del reflejo culterano en este tipo de festejos puede verse en Justas y Certámenes poeticos en Murcia (1635), de Antonio Pérez Gómez y Manuel Muñoz Cortés, Murcia, Academia Alfonso X el Sabio, 1958-59, 3 vols.

'Véase la excelente edición de José Manuel Blecua del Cancionero de 1628, Madrid, 1945. pp. $57-8$.
} 
influencia de Góngora en el Retrato de las Fiestas, de Luis Díez de Aux, que se celebraron en Zaragoza, en 1614, en honor de Santa Teresa. De otras se hace imposible un análisis estilístico, dado que sólo conservamos de ellas algunas referencias, como es el caso del Certamen poético que la Universidad de Zaragoza consagró a... Don Pedro de Apaolaza (1642) ${ }^{6}$. Pero fuese cual fuese su motivación, la huella de Góngora parece dominar y teñir la mayor parte de los certámenes aragoneses. Se conmemoraban, allí como en el resto de España, esponsales reales, beatificaciones. cargos inquisitoriales, festividades de la Iglesia, etc. Detrás estaban la universidad, las órdenes religiosas, las academias, las cofradías y la nobleza. A veces, son símbolo final de un capítulo de ambiciones políticas regionales, como la que llora la muerte de Baltasar Carlos. Se podrían aplicar aquí las palabras de M. de Schoezer, a propósito de las fiestas públicas en la Francia Renacentista, cuando señala cómo el arte se pone al servicio de una propaganda ideológica que condiciona su misma celebración ${ }^{7}$.

Convenía asentar esta fuerte influencia culterana, que se impone como moda hasta en la poesía más oficial, para ver hasta qué punto tal realidad distaba mucho de ser aceptada por quienes ostentaban el papel de jueces y dictaban las reglas a los poetas. Situación que provocó más de una ambigüedad, si tenemos en cuenta que algunos, como Andrés de Uztarroz y Felices de Cáceres, hacen un doble papel, al aparecer unas veces como parte del jurado, y otras, aspirando a ser premiados con sus versos. Su filiación gongorina no les quita el seguir el camino de poetas más ortodoxos, cuando se trata de establecer quiénes deben ser los imitados. El hallazgo en la Biblioteca Nacional de una serie de carteles convocando a distintas justa me permitirá ampliar las bases conocidas y establecer las formas métricas y los autores elegidos como prototipo. Dejo del lado la valoración y análisis de los poemas presentados, por razón de espacio. Aunque conviene tener en cuenta la referencia de quien había acudido en 1595 a Zaragoza a la Justa Poética de San Jacinto, como un poeta más, cuando señala en el Quijote (II, XVIII):

"y si es que son de justa literaria, procure vuestra merced llevar el segundo premio; que el primero siempre se lleva el favor o la gran calidad de la persona, el segundo se le lleva la mera justicia, y el tercero viene a ser el segundo, y el primero, a esta cuenta, será el tercero,...”

${ }^{6}$ R. del Arco, La Erudición Española, pp. 249-250. El manuscrito con los poemas se ha perdido.

' Cfr. Jean Jacquot, Les Fêtes de la Renaissance, París, 1960, p. 15. Véase F. López Estrada, «La relación de las fiestas por los mártires del Japón, de doña Ana Caro de Mallén (Sevilla), 1628", Libro-Homenaje a Antonio Pérez Gómez, Cieza, 1978, pp. 51-69. 
Respecto al planteamiento de los metros y estrofas propuestos, suele mantenerse una jerarquía de valores, tanto más lógica, si tenemos en cuenta que iba ya implícita en las consideraciones de las poéticas del momento, como se desprende de la de Rengifo, cuando distingue en el capítulo XL:

"Todas las composiciones de que hasta aquí hemos tratado, son propias de nuestra España: las quales aunque si son elegantes, suaves y graciosas, no se puede negar, sino que las Italianas las hazen gran ventaja" ".

Cuentan, por un lado, los metros latinos y por otro, los castellanos, sin que se utilizase en ningún caso el catalán, como ocurrió en la Academia Pítima contra la ociosidad ${ }^{9}$. Para las composiciones latinas, se proponen elegías, dísticos (de dos, siete, ocho, nueve y diez versos), hexámetros (o hexámetros y pentámetros elegiacos alternos), epigramas (con atención al número de dísticos) y empresa con mote latino. A veces, no se especifica el metro y se señala simplemente que deberá tratarse de una composición latina. En las castellanas, aparecen normalmente las estrofas de arte mayor destacadas en primer lugar, como ya he dicho, siendo el soneto el elemento imprescindible, seguido en número de frecuencia por la glosa que, como era lógico, venía ya propuesta por los jueces para servir de pie a los concurrentes. La calidad es escasísima y tienen estas piezas un carácter funcional que se evidencia en el mismo Arte poética de Rengifo (cap. XXXVI):

"Proponese primeramente un Texto, o Retruecano (que assi le llaman algunos Poetas, de uno, o dos, o quatro versos, mas o menos, como quisiere el que lè pone: el qual encierre algun concepto agudo, y sentencioso, y lleve tales consonantes, que se puedan hallar otros: porque los demas, sino es que se hiziesse de industria por picar y dar en que entender a los Poetas, seria desatino.... ${ }^{10}$.

"Juan Díaz de Rengifo, Arte poética española, Salamanca, 1582. Sigo la de Madrid, 1606, p. 47. En p. 48 dice: «El soneto es la mas grave composicion que ay en la Poesia Española». Para este «decoro" métrico, también p. 38: "No ay cosa mas facil que hazer un Romance, ni cosa mas dificultosa si ha de ser qual conviene".

- Esta academia se reunió, en el verano de 1608, en Fréscano, en casa de don Gaspar Galcerán de Castro y Pinós, conde de Guimerá, de origen catalán (C.fr. Latassa, Biblioteca, I, p. 566), aunque vivió en el Coso zaragozano. El ms. 9396 de la B. N. conserva sus actas y estatutos. La sola presencia del duque, así como la del licenciado Aragall y Alejandro Calast, justifican la utilización del catalán, véase José Sánchez, Academias Literarias del Siglo de Oro español, Madrid, 1961, pp. 252 y ss. y W. F. King, Prosa novelistica y Academias literarias en el siglo XVII, Madrid, 1963, pp. 65-7. Cerca de Fréscano precisamente, en Alcalá de Ebro y Pedrola, situaría Cervantes su conocido episodio aragonés del Quijote. Y más próximo a Zaragoza, Monzalbarba, residencia de Lupercio (vid. nota 27), estrecha esa geografia, tan literaria.

${ }^{10}$ Ed. cit., p. 47. 
Así, en el cartel de la Contienda poética que propone la Cofradía de la Sangre de Cristo para exercitar su devoción (Zaragoza, 1621), se propone a los poetas glosar estos versos, traducción de la estrofa *Arbor decora et fulgida" del himno litúrgico "Vexilla Regis", vinculado al tiempo de Pasión y a los símbolos de esta Cofradía:

$\quad$ "Mirad la gloria que inspira
esta purpura Real
que al madero ignominioso
(desde que se orno con ella)
damos el honor que a Dios.»"

Los romances, octavas, tercetos, liras, décimas, redondillas y silvas son otros tantos modelos, sujetos siempre a un tema, religioso o civil, en conexión directa o forzada con el asunto del certamen. En ese mismo de la Cofradía de la Sangre de Cristo, las octavas del tema séptimo debían ser traducción del himno litúrgico del Adviento "Alma redemptoris mater" y se añade además una estrofa de libre elección, en poema jocoso a los soldados que velaron el sepulcro de Cristo. Abunda la emblemática, con la proposición de numerosos jeroglíficos y emblemas, empresas y epigramas, que contribuían, además, a la fastuosidad de las celebraciones, tan unida frecuentemente a la mitología clásica, que ejercía un doble papel, decorativo y propagandístico ${ }^{12}$.

Mención aparte merecen las canciones, que llevan en los carteles una apostilla, indicando, en detalle, formas y autores. Es evidente que las justas aragonesas se corresponden con lo señalado por Segura Covarsi en su estudio de La canción petrarquista en la lírica española del Siglo de Oro ${ }^{13}$. Se trataba entonces de proponer autores como ejemplo para las

"El ms. 9572, fol. 6 de la B. N. coincide con la relación del certamen, publicado en Zaragoza en 1623 por Felices de Cáceres: El cavallero de Avila... Con un Certamen Poetico por la Cofradia de la Sangre de Christo.

12 Así lo apunté en mi tesis cit., pp. 402 y ss. Véase Jean Jacquot, Les Fêtes de la Renaissance, ed. cit. y de J. A. Maravall, "La literatura de emblemas en el contexto de la sociedad barrocam. Teatro y Literatura en la sociedad barroca, Madrid, 1972, pp. 149 y ss. y -Objetivos políticos del empleo de medios visuales., apéndice a $L a$ cultura del barroco, Barcelona, Ariel, 1975. Para la huella de Akiato, Giuseppina Ledda, Contributo allo studio della letteratura emblematica in Spaña (1543-1613), Universidad de Pisa, 1970. Queda por estudiar la función de los emblemas en las fiestas públicas españolas. Cabe destacar que en las aragonesas reina la misma confusión de términos que ya llevaban implícitas las distintas definiciones que se emitieron en la época (véase Aquilino Sánchez Pérez, La literatura emblemática española. Siglos XVI y XVII, Madrid, 1977, p. 53).

${ }^{13}$. Madrid, 1949, pp. 178 y ss. Analiza pocas justas, pero sus conclusiones pueden generalizarse y coinciden con las que aquí apuntamos, excepción hecha de las alusiones a los Argensola, propuestos por razones obvias. 
canciones, siendo Petrarca modelo indiscutible, al que siguen los líricos del siglo xit que son considerados ya como clásicos para el ars imitatoria. La influencia petrarquista en nuestra poesía es tan evidente y amplia que no puede ser mostrada como argumento único. Creo que la razón práctica podría deducirse de la codificación que de sus canciones se hace en la poética del Siglo de Oro, proponiéndolo como imitación constante para las distintas variantes. Volviendo una vez más a Rengifo, su Arte ofrece un muestrario que abarca todas las posibilidades estróficas y métricas. El nombre aparece desde el mismo enunciado («... a las quales el Petrarca llama siempre Canciones"), por más que al recomendar "arte y prudencia para lo hazer", recuerde a Boscán y Garcilaso "con ser tan señalados Poetas: cuyas Canciones, si bien las miramos, no discrepan casi en nada de las del Petrarca" ${ }^{14}$. De ahí que Garcilaso aparezca como digno de ser imitado en las canciones primera, quinta, sexta y decimonovena, así como en las liras ${ }^{15}$ y en la rima encadenada. Boscán lo acompaña en las canciones sexta, séptima, octava, decimonovena y en la veinticinco ${ }^{16}$, pero su aparición no deja de ser relativa, como las alusiones a Dante, "Guido Calvacante" y M. Gino ${ }^{17}$, si tenemos en cuenta que Petrarca se alza como maestro primero en el arte de treinta tipos de canciones, siete "ballatas" y cuatro madrigales. Rengifo cuida además el aspecto extratextual de la poesía, no sólo en la trampa posible que se puede tender al poeta no avisado con las referidas glosas, sino en lo que se refiere a esta poesía de justas a la que parecen ir dedicadas estas indicaciones en la canción treinta:

"Hazense estas sextinas para ostentacion, y aparato, quando se piden en Carteles, o quando en alguna solene fiesta quiere el Poeta sembrar los tapizes de varias Poesias, o en otras ocasiones que se ofrecen.. '"

Que sus recomendaciones fueron bien atendidas es evidente, como veremos, en el tipo de poemas que se propuso en las justas aragonesas. $Y$ más si atendemos a la Justa que en 1618 celebró Calatayud «en

${ }^{14}$ Ed. cit., cap. LIX, p. 64.

"Ibid, cap. LXIII, p. 90: «Algunos quieren dezir, que la invento el ilustre Porta (arcilasso de la Vega y que el que no aya sido su inventor fue a lo menos uno de los Poetas que primero la usaron», citando, como era lógico, «Ad Florem Gnidi».

${ }^{10}$ Destaca en ésta última la referencia a que los inodelos de la canción $90^{2}$ y $100^{2}$ de Boscán, comparados con la canción 28. ${ }^{2}$ de Petrarca, difieren en que "Boscán la añadio un verso, y vario un consonante en los Pies postreros* (Arte, p. 79).

1" Propuestas para las canciones 10,11 y 13. A ello hay que añadir la referencia a una égloga de Sannazaro para la "rima encadenada”.

${ }^{1 *}$ Ed. cit. p. 83. 
defensa de la pureça de la Inmacula Concepçion", mantenida y premiada por don Sancho Zapata, y publicada un año más tarde en Zaragoza ${ }^{19}$, que, entre sus siete certámenes, propone en el segundo siete rimas encadenadas de once versos que a la quinta o séptima sílaba del segundo corresponda el consonante del fin del primero, según el Arte poética de Rengifo ${ }^{20}$.

La primera referencia a Petrarca la encontramos en un certamen oscense que se celebró en 1609 en la Traslación de las reliquias del Glorioso Pontífice San Orencio: fue promovido por la Universidad y publicado más tarde por Francisco Diego de Aynsa y de Iriarte (Huesca, 1612). Entre los seis certámenes propuestos, el segundo es una canción imitando a la de Petrarca "Di pensier in pensier, Di monte in monte", ${ }^{21}$ al piadoso celo que Huesca mostraba por el santo. Aquí no se hace perceptible la huella de Góngora, a pesar de que un futuro seguidor del poeta cordobés, Luis Díez de Aux, acudiese con sus versos, junto con un anticulterano declarado, fray Tomás. Ramón, que presentó tres jeroglíficos ${ }^{22}$.

Entre las celebradas en Zaragoza, encontramos una alusión a la canción petrarquista en el Certamen poético por las fiestas de la traslación de la reliquia de San Ramón Nonat, publicado allí por Francisco Gregorio de Fanlo en 1618, pero celebrado un año antes. Debía seguirse la ventiocho de Petrarca ${ }^{23}$, aunque el modelo debía ir referido, como en las demás, sólo a las formas más externas, porque entre el centenar de concursantes hay ejemplos claros de filiación gongorina, como es el caso de fray

${ }^{19}$ Analicé la justa en la tesis cit. Véase Juan de Moncayo, Rimas, ed. cit., p. XXIV , n. 52. Fn esa ciudad existió una academia literaria, según se deduce de un romance *A la Academia de Calatayud", poema mitológico de escaso valor que se encuentra en el ms. 3811, fols. 13-14 de la B.N. En los fols. 12 y 14 hay más composiciones poéticas que podrían ser asunto de ese cenáculo, a juzgar por uno de sus títulos: «A la fuente de Calatayud".

${ }^{20}$ Ed. cit., cap. LXIV, p. 91; allí encontramos los ejemplos aludidos de Garcilaso y Sannazaro.

${ }^{21}$ Segura Covarsi (op. cit.) señala la misma canción petrarquista como modelo de otra justa. Corresponde a "Soneti e Canzoni in vita di madonna Laura», CXXIX, Le Rime, ed. de G. Garducci y S. Ferrari, Florencia, 1956, p. 204.

${ }^{22}$ Fray Tomás Ramón publicó en Zaragoza, 1635, una Nueva premática de reformación contra toda serie de abusos, entre ellos los cultistas, a los que dedica un apartado. Atacó el confusionismo de los sermones hinchados y es un buen precedente del Fray Gerundio de Campazas.

${ }^{23}$ En este certamen se tiende a la búsqueda del esdrújulo sonoro, del vocablo culto, de la sintaxis dislocada. Así lo testimonian el soneto de Francisco de Boil, las décimas de Juan Francisco Serrano y el soneto de Francisco de Borja en los preliminares. Francisco Gregorio de Fanlo, que hace la relación, es el caso más evidente de su incorporación estilistica al gongorismo (pp. 1-43). 
Pedro Enrique Pastor, que entre cultismos y formas típicamente gongorinos desliza un "a fuentes de Rubi, puntas de plata", de inconfundible sello, con otras herencias similares:

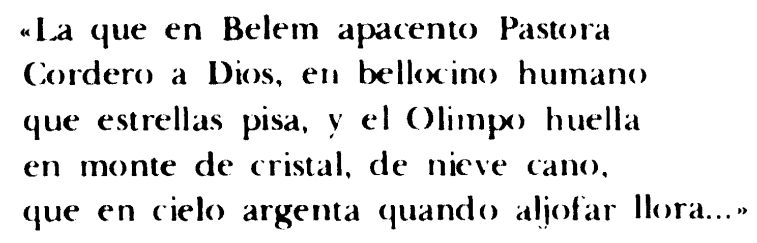

Posteriormente, un Certamen poetico que un cavallero de la ciudad de Tarazona muy devoto de los gloriosos santos Ignacio y Xavier y de la Compañia de Jesus propone a todos los buenos ingenios para las fiestas de sus canonizaciones añade una alusión más. He tenido conocimiento de su existencia por el cartel que se encuentra en el ms. 9572 de la Biblioteca Nacional, folio 4 , impreso en la Universidad de Zaragoza en 1622. Con doce certámenes, ofrece más temas y metros que el resto de los aragoneses y va firmado en Tarazona a 22 de mayo de 1622, bajo los lógicos auspicios del Colegio de la Compañía de Jesús al que se debían remitir los ejemplares antes del ventidós de mayo. El primer certamen propone una canción en siete estancias con un epílogo "como la 18 del Petrarca que comiença Perche la vita e breve", con tres premios: un relojito de Alemania, un bolsillo de ámbar con canutillo de oro y unas medias de seda, a los tres que mejor describiesen la visión de San Ignacio a las puertas de Roma, antes de que el Papa le confirmase su religión.

$Y$, por último, es Huesca nuevamente la que en 1650 muestra, en la referida Palestra numerosa austriaca, idénticas preferencias, proponiendo en el asunto tercero una canción real de seis estancias, a semejanza de la ventiocho de Petrarca, para cantar la pena de los reyes de España en su ocasional separación. En ella destacaron comprobados seguidores de Góngora, que dejaron en los versos presentados la huella de su estilo: desde el que hace la relación, Amada y Torregrosa, a Juan Lorenzo Ibáñez de Aoiz, pasando por Juan Nadal y fray José de Sierra y Vélez de Corella, del que se incluye un Panegirico Epitalamico, herencia clara del himeneo de las Soledades.

Garcilaso consta en 1608, en un olvidado certamen que la Universidad de Zaragoza celebró en honor de fray Jerónimo Javierre ${ }^{24}$, para

\footnotetext{
24 B. N., ms. 9572, fol. 10, “Cesaraugustanae Academiae, edictum ad literarium certamen in laetitiam illmi et Reverendissimi Domini D. Hieronymi Xabierre ad Sacram Purpuram coaptavi». Impreso en Zaragoza por Lorenzo de Robles, 1608. Se destaca en este desconocido cartel la función extrapoética de tales festejos. En las propuestas se ha de
} 
una canción "de cuatro estanças igual a la de (arcilaso "El aspereza de mis males quiero". Fsta justa ofrece además el interes que da la presen(ia. como secretario de la misma, de Lupercio Leonardo de Argensola. Fs posible que se deban a él algunos criterios vertidos en el texto del cartel, así como la propuesta de una canción de siete estancias, glosando, de Francisen de Figueroa, "Cuytada naverilla/por mil partes hendida" 25 , pues resulta curioso que se postule así sobre las redondillas en un cartel de reclamo poético:

"Aungue el verso, que vulgarmente llaman italiano. a tan antiguo en Fopanat.

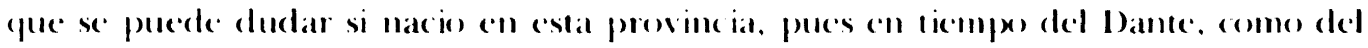
se colige, competian los Poetas lemosines, con les italianos: lodavia es mas propies de España, el que llaman Rt.DONDIL.L.AS, tan acomodade a nuestla lengua, que no se acompaña con ottat y assi poco leliemente le an usade proctas lonsanon, es justo pues que tenga aqui lugar: pidense quarenta redondillas de quatro pies. semejantes en la contestura a esta de don Diego de Mendexal
Ay langa esperanga lana quantos dias ha que roy engañando el dia de oy
y esperando el de mañanal"

y que con la alusión horaciana, tan ligada a los gustos personales de l.upercio I eonardo, se muestre una flexibilidad de criterio no muy frecuente en las justas:

"No crean los que hubiexen de escrivir, que como ha Historiadores pretendemos obligarles a discurrir por todos los Themas que les proponen. sin dexar cosa dellos: no se aten tanto a estos preceptos, que falten al espiritu de la poesia; y por huir de un vicios incurran en otros, in ritum ducit culpo fuga, dize Oracios. 26.

alabar a los obispos zaragoranos, al rey, al Duque de lerma y a Pedro (corbunat que en el cetavo certamen lleva un "jeroglifico o emblema", como patrón de la liniversidad. R. del Arco señala que el 8 de febrem de 1608 se interpretó en el pation de la Diputación lat comedia (iremon de las Letras por la compañia de Melchor de Leoon. thl motivo cera el mismo. Pero el certamen fue posterior, pues los poemas debian presentarse ('ll marm de ese ano (La Erudición Eispañola, p. 70).

${ }^{25}$ Fis la canción III de Francisco de Figueroa, Poesias, Madrid, 1943, pp. X/-4. Fixiste en un ms. del s. XVIII, como "Oda 14, lib. I de Horacio" (Simón Diay, BL.H, X. II." 1716. Madrid, 1972). La elección parece cosa de Lupercio Leonardo, por ko singular. No se olvide, sin embargo, la importancia de este "divinow en su tiempo, tan lejos de nuestra apreciación actual (Cir. Rodriguez. Moñino, Construcción critica y realidad histirica en la presien española de los siglos XVI y XVII, Madrid, 1968, pp. 21 y ss.).

${ }^{26}$ Recuérdese la loa de Lupercio Leonardo a su Alejandra (:1581-5:), cuando reconece que "la edad se ha puesto de por medion, rompiendo el respeto a las reglas aristotélicas (véase Sánchez Escribano y Porqueras Mayo, Preceptiva dramática española del Renacimiento y del Barroco, Madrid, 1971, p. 68). Concuerda con la tendencia de Bartolomé Leonardo a no dejarse esclavizar por las reglas. Para el horacianismo del primero: Rimas, ed. de J. M. Blecua, Madrid, 1972, p. XXIII. 
Este dato biográfico ilumina un poco esos años de retiro en su finca de Monzalbarba, aquejado de una parálisis casi total. Asistimos así a su vuelta a la vida social zaragozana y al nuevo giro que experimentaría al ofrecerle ese mismo año de 1608 la secretaría del virreinato de Nápoles el Conde de Lemos ${ }^{27}$.

Pero, volviendo a Garcilaso, en 'ina justa que Zaragoza celebró en 1614 por Santa Teresa de Jesús, para añadirse a las muchas que se celebraron en toda España con motivo de su beatificación, se propuso una canción de cuatro estancias y un epílogo, como la que empieza «El aspereza de mis males quiero" ${ }^{28}$. Saldría un año después de las prensas zaragozanas, publicada por el gongorino Luis Díez de Aux, encargado de relatar otro certamen que en 1619 propone también a Garcilaso para ensalzar en una canción las virtudes del inquisidor fray Luis de Aliaga ${ }^{29}$. "El dulce lamentar de dos pastores" será requerido nuevamente en la ya citada justa de la Cofradía de la Sangre de Cristo para las seis canciones que debían tratar el asunto tercero.

Goza así Garcilaso de una consideración semejante a la de Petrarca, precedida, en este caso, por la estimación que demuestra un impreso del ms. 9572 de la B. N., folio 11 , con fecha de uno de agosto de 1585: «Cartel de los muy ilustres señores cofrades de la cofradia del inclito martyr San Lorenço de la ciudad de Huesca...», con las propuestas para un certamen celebrado ese año y que pide, en segundo lugar, nueve estancias, imitando la de Garcilaso "Si de mi baja lira» 30.

Curiosamente Lupercio y Bartolomé Leonardo de Argensola se convierten en modelos, sustituyendo a los citados, a partir de 1643. Su

${ }^{27}$ Rimas, ed. cit., p. XIV.

${ }^{28}$ En el ms. 9572 de la B.N., fol. 13, he encontrado una «canción real» impresa que completa la documentación sobre el certamen. Empieza "España de preciosas pıedras rica* y es de Luis Díez de Aux. También se alude al certamen en el Compendio de las solemnes fiestas que en toda España se hicieron en la beatificación de N.B.M. Teresa de Jesus, de fray Diego de San Jose, Madrid, 1615, fols. 37-44.

${ }^{29}$ Se conserva en el Compendio de las fiestas que ha celebrado la imperial ciudad de Caragoça, por aver promovido... Filipo Tercero... a (...) Fray Luis Aliaga... en el... cargo... de Inquisidor General de España, Zaragoza, 1619. En la B. N., ms. 9572, fol. 7, existe el cartel impreso. Y en el fol. $8 \mathrm{del} \mathrm{mismo,} \mathrm{un} \mathrm{romance} \mathrm{sobre} \mathrm{el} \mathrm{certamen,} \mathrm{que} \mathrm{muestra} \mathrm{el} \mathrm{nivel} \mathrm{encomiástico}$ de la justa y sus relaciones extrapoéticas: «aliaga, esta presidencia/rija y goza un siglo entero/para que acabe a Lutero».

30 Desconocido por la crítica, muestra algunos datos de interés. Lo publica la Universidad de Huesca y propone cuatro certámenes, uno de ellos en latín. A los tres que mejor remedasen a Garcilaso se les daba: un tafetán blanco, un espejo y una paráfrasis latina que hizo Arias Montano de los versos sobre el tema que propone el certamen. Pedro de Lastanosa, canónigo y catedrático, sería el encargado de entregar los premios. Las obras de Castillejo serían el reclamo para le mejor glosa. 
relación con las justas poéticas es de sobra conocida, así como la de Gabriel Leonardo y Albión, que fue secretario de una de ellas ${ }^{31}$. Pero creo interesante señalar también, que en la Justa poetica por la Virgen Santissima del Pilar (Zaragoza, 1629) aparecen unos dísticos de Bartolomé Leonardo de Argensola, que parecen contradecir la idea de que «jamás se le ocurrió la idea de escribir versos latinos":

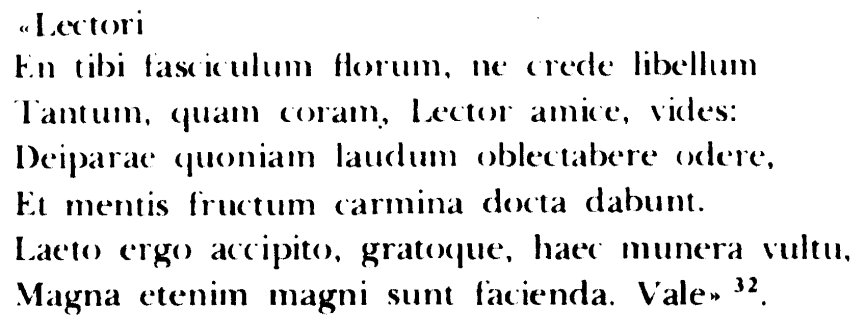

Al lado, en el folio 1, Felices de Cáceres inicia la introducción al certamen con estos versos que apunto, tan lejanos de la poética del ilustre canónigo:

"El aureo Apolo, el delfico Monarca,
Suspensiva lisonja de la Parca,
que dando acento a las hermanas nueve
Calma los vientos, y los inontes mueve
Con cadencias sonoras
De cantos dulces, en alegres horas;"

En ellos vemos claramente esa dicotomía que pervive entre el respeto por los maestros considerados como clásicos y las nuevas tendencias, de indiscutible línea gongorina.

El Certamen poético de Nuestra Señora de Cogullada, celebrado en Zaragoza en 1643, aunque publicado un año más tarde, propone para el tercer asunto cuatro estancias a imitación de "Ya la primera nave fabricada" ${ }^{33}$ de Bartolomé Leonardo. También se conserva del acto el cartel correspondiente (ms. 9572 de la B. N., fol. 2), y aunque algunos de sus jueces eran más que sospechosos de gongorismo (Juan de Funes y Villalpando, marqués de Ossera, y Juan Francisco Andrés de Uztarroz), así como uno de los secretarios, Juan de Iribarren, la fidelidad regional no les impide seguir por otros senderos. Se establece, aquí como en las otras

\footnotetext{
${ }^{31}$ Véase L. Leonardo, Rimas, ed. cit., pp. XI y ss. y Bartolomé Leonardo, Rimas, ed. de J. M. Blecua, Madrid, 1974, I, pp. XL.VI. Sobre el papel de Gabriel Leonardo como albacea de su tio Bartolomé, véase la ed. cit., p. XIX.

32 J. M. Blecua (Rimas I, ed. cit., p. XXIV) dedujo esa postura antilatina de su «Epís tola a Fernando de Soria».

${ }^{33}$ Bartolomé Leonardo, Rimas, I, pp. 246-250. Figura en el citado Cancionero de 1628. fol. 365, según señala Blecua, y con variantes de peso.
} 
justas, una clara diferencia entre los modelos estróficos y las tendencias estilísticas de quienes intervienen. El mismo Iribarren da temprano testimonio de ello, cuando abre la relación de los festejos «En campo de esmeraldas coronado", para establecer homenaje a quien era algo más que modelo oficial propuesto. En 1646 la Contienda poética raragozana por el príncipe Baltsar Carlos, dirigida y relatada por Andrés de Uztarroz, confirma en sexto lugar una canción de cuatro estancias, sobre la de Lupercio Leonardo "A quien no espantara la andiente pyra" ${ }^{34}$. Y Bartolomé Leonardo es propuesto en 1659, en segundo lugar, para una canción de cuatro estancias, como la suya que empièa "Oy quiere el cielo" ${ }^{35}$. Se trata del Certamen celebrado para conmemorar en Zaragoza la canonización de Santo Tomás de Villanueva, que saldría a la luz un año más tarde con la relación de Gabriel Manuel Abás y Nicolau. Una última referencia a Bartolomé viene en el cartel convocando a un Certamen literario que propone la insigne ciudad de Zaragoza en el nacimiento del Serenissimo Carlos Principe de las Españas (ms. 9572 de la B. N., fol. 26), referido, sin duda, a uno de tantos festejos con que la ciudad celebró la venida al mundo de Carlos 11 en 1661. Fin el tercer asunto se pide una canción en el metro de la de Bartolomé Leonardo de Argensola "En tanto que nos haze tu esperanga". (ion la particularidad de este sorprendente premio:

"Tendrán de bueno las peores Poessías de cada assunto las (Obras de !os loconardos."

Es posible que otros certámenes, de los que sólo quedan moticas aisladas, mostrasen parecidos maestros para los temas de las canciones ${ }^{36}$. Estas, quedarían marcadas en su realización individual por el

\footnotetext{
34 "Canción al martirio de San Lorenzon, Rimas, ed. cit., p. It.t. Fin el ms. 9572, fol. 383, hay un soneto "Al túmulo que la ciudad de Caragexa hi\%o para celebrar las exequias funerales del principe Baltasar (arlosw, precedido de un lango pocema incélito, posiblemente de Andrés de Uatarm\% (Ibid., fols. 379-342).

"Bartolomé Leonardo, Rimas, ed. cit., II, p. 21: «t.n la transliación de una reliefuia de la Iglesia de Roda a la de Barbastro...". Sobre la existencia de un certamen literario en Barbastro con tal motivo, en mi tesis cit., pp. 563 y ss. Pala el catalogo de mexlelos literarios, interesa la opinión de un poeta de esa ciudad, Alonso de la Sicrra, que en, $\mathrm{El}$ Solitario Poeta (Zaragora, 1605), señala entre sus favoritos a Ariosto, Dante, (iarcilisso, Ercilla, Martír te Bolea, Franciso de Lrrea, Zapata, los Leonardos, Quevedo, (ióngona, Artieda, Tárrega. Padilla y otros, meclándose, como en la Agudeza, en las academias y en las justas de la región, en el culto por propios y extraños.

${ }^{36}$ Me refiero al certamen de E.pila (B. N., ms. 2883, fol. 383) een la traslación del SSmo. Sacramento a la Iglesia de las monjas de la Purissima Concepcion. Hay que anotar que también se conservan en el citado ms. dos certámenes marginales, uno en Tudela (1629) y otro en la villa de fon\% (1616) (fols. 5 y 9, respect.). También interesa el P'apel del
} 
modelo propuesto por los jueces, pues tal y como concluye Sharon Ghertman su análisis comparativo entre la canción petrarquista y la de Garcilaso, el modelo estructural afectó en el siglo xil a diferentes aspectos del lenguaje poético: "its metrical organization or rhythmic patterns, its semantic recurrences, and its syntax" ${ }^{37}$, redundando en la atinada visión que Dámaso Alonso expuso a propósito de la correlación y la plurimembración como secuela de la devoción petrarquista ${ }^{38}$.

De lo dicho, se desprende una distinción clara entre lo que se entiende como modelo propuesto a los poetas desde los círculos oficiales que organizan los festejos (cofradías, universidades, academias literarias, órdenes religiosas, etc.), y las tendencias poéticas de entonces, que más allá del afecto por maestros indiscutibles como Petrarca, Garcilaso y Figueroa, o Lupercio y Bartolomé, tan de casa, se decantaron muy pronto por la poesía de don Luis de Góngora. Se constituye así Aragón en una de las regiones más fieles a su escuela, aunque hasta las historias más recientes mantengan ese mismo criterio oficial por el que se regían las justas y consideren que la cosa no pasó de los Argensola, silenciando los nombres de otros muchos poetas que forman esa historia no escrita a la que se refería en su lección don Antonio Rodríguez Moñino, cuando señalaba que “La poesía de los siglos de oro en España está fragmentada en islotes geográficos casi totalmente independientes entre sí y poco permeables" ${ }^{39}$, muy lejos de esa "conciencia nacional colectiva" que se deduce de la crítica al uso.

Alrora EgIDO

Universidad de Zaragoza

ms. Eg. 327 del Museo Británico, fol. 314, que alude a unas justas deshechas que iban a celebrarse el 7 de abril de 1670 en Karagova.

${ }^{37}$ Sharon Ghertunan, Petrarch and Garcilaso. A Linguistic Approach to Style, Londres, Támesis Boxks, 1975, p. 129. (oıno muy bien señala en el cap. Il, la importancia de Rengifo en la historia de la canción radica en su pretensión reguladora, inás allá del libre albedrio de los poetas que le concede Sánche\% de Lima (El arte poética en romance castellano, ed. de Balbín Lucas, Madrid, 1944), coincidiendo con el afán de Lópè. Pinciano, en su Philosophia antigus poética (1596), por avisar a los poetas para que consulten los textos antes de juzgar sobrc las licencias poéticas de la stanza. Los buenos inodelos y el arte de la imitatio harían el resto.

3* Dámaso Alonso, art. cit., p. 89 y Poesía Española. Ensayo de métodos y limites estilisticos, Madrid, 1966. S. Ghertman discute el métodos de D. Alonso en el cap. III (opus cit., pp. 9-13), intentando s"1x'rarlo desde una base estructuralista, basada fundamentalinente en Michael Rifaterre, Essais de stylistique estructurale (París, 1971).

${ }^{34}$ Rodríguez Moñino, opus cit., p. 56, R.O. Jones, con su frecuente agudeza en cuestiones poéticas, discurre por estos caminos en su Historia de la literatura española, 2. Siglo de Oro: proso y poesía, Barcelona, 1971. Agradeaco a Víctor García de la Concha las sugerencias que me ofreció tras la paciente lectura de este artículo. 